\title{
Light-Induced Changes in Spike Synchronization between Coupled ON Direction Selective Ganglion Cells in the Mammalian Retina
}

\author{
Jessica M. Ackert, ${ }^{1}$ Synphen H. Wu, ${ }^{2}$ Jacob C. Lee, ${ }^{1}$ Joseph Abrams, ${ }^{1}$ Edward H. Hu, ${ }^{1,2}$ Ido Perlman, ${ }^{3}$ and \\ Stewart A. Bloomfield ${ }^{1,2}$ \\ Departments of ${ }^{1}$ Ophthalmology and ${ }^{2}$ Physiology and Neuroscience, New York University School of Medicine, New York, New York 10016, and \\ ${ }^{3}$ Department of Physiology and Biophysics, Technion-Israel Institute of Technology, Technion City, Haifa 3200, Israel
}

\begin{abstract}
Although electrical coupling via gap junctions is prevalent among ganglion cells in the vertebrate retina, there have been few direct studies of their influence on the light-evoked signaling of these cells. Here, we describe the pattern and function of coupling between the ON direction selective (DS) ganglion cells, a unique subtype whose signals are transmitted to the accessory optic system (AOS) where they initiate the optokinetic response. ON DS cells are coupled indirectly via gap junctions made with a subtype of polyaxonal amacrine cell. This coupling underlies synchronization of the spontaneous and light-evoked spike activity of neighboring ON DS cells. However, we find that ON DS cell pairs show robust synchrony for all directions of stimulus movement, except for the null direction. Null stimulus movement evokes a GABAergic inhibition that temporally shifts firing of ON DS cell neighbors, resulting in a desynchronization of spike activity. Thus, detection of null stimulus movement appears key to the direction selectivity of ON DS cells, evoking both an attenuation of spike frequency and a desynchronization of neighbors. We posit that active desynchronization reduces summation of synaptic potentials at target AOS cells and thus provides a secondary mechanism by which ON DS cell ensembles can signal direction of stimulus motion to the brain.
\end{abstract}

Key words: retina; synchrony; gap junctions; coupling; ganglion cells; inhibition

\section{Introduction}

Electrical synaptic transmission via gap junctions underlies direct and rapid intercellular neuronal communication (Goodenough et al., 1996; Kumar and Gilula, 1996; Sáez et al., 2003). With the recent discovery of the gap junction constituent connexin proteins (Beyer et al., 1990; Kumar and Gilula, 1996) and the junction-permeant biotinylated tracers (Vaney, 1991), there is now mounting evidence that electrical synapses are prevalent throughout the CNS and thereby play a major role in shaping and transmitting neuronal activity.

An elegant example is the retina in which each of the five major cell types are coupled to their neighbors (Vaney, 1991, 1994; Xin and Bloomfield, 1997). These junctions are highly plastic, with their conductances affected by changes in ambient illumination acting through the neuromodulators dopamine and nitric oxide (Mangel and Dowling, 1985; DeVries and Schwartz, 1989; Umino et al., 1991; Bloomfield et al., 1997). In the proximal retina, ganglion and amacrine cells show a rich variety of electrical synapses (Vaney, 1991, 1994; Xin and Bloomfield, 1997). This

Received Nov. 1, 2005; revised March 6, 2006; accepted March 14, 2006

This work was supported by National Institutes of Health Grant EY07360 and Research to Prevent Blindness. We thank Drs. Jerry Simpson and Mickey Ariel for helpful discussions.

Correspondence should be addressed to Dr. Stewart A. Bloomfield, Department of Ophthalmology, New York University School of Medicine, 550 First Avenue, New York, NY 10016. E-mail: blooms01@med.nyu.edu. D01:10.1523/JNEUROSCI.0496-06.2006

Copyright $\odot 2006$ Society for Neuroscience $\quad$ 0270-6474/06/264206-10\$15.00/0 coupling appears to underlie coherent firing of ganglion cell neighbors, ranging from broad correlations spanning tens of milliseconds to finely tuned spike synchrony with 1-3 ms latencies (Mastronarde, 1983; Meister et al., 1995; Brivanlou et al., 1998; DeVries, 1999; Hu and Bloomfield, 2003). Concerted firing accounts for up to one-half of retinal spike activity, suggesting that electrical coupling plays an important role in encoding visual information (Castelo-Branco et al., 1998; Schnitzer and Meister, 2003). Yet, this role remains unclear, because there have been few studies of how electrical synapses shape the responses of retinal neurons, particularly those of the output ganglion cells.

A unique subtype of ganglion cell is the direction selective (DS) cell, which responds vigorously to stimulus movement in a preferred direction, but weakly to movement in the opposite or null direction (Barlow et al., 1964; Oyster, 1968). The ON subtype of DS cell projects to the accessory optic system (AOS) (Oyster et al., 1980; Buhl and Peichl, 1986; Pu and Amthor, 1990; Rosenberg and Ariel, 1991) where their directional signals underlie the optokinetic response, a compensatory eye movement that stabilizes an image on the retina during slow head rotation (Simpson, 1984; Stahl, 2004).

Here, we examined the role of electrical coupling in generating the responses of ON DS cells to moving visual stimuli. Neighboring ON DS cells were found to be coupled indirectly via gap junctions made with a subtype of polyaxonal amacrine cell. This coupling underlies the synchronized activity of neighboring ON 
DS cells. Interestingly, DS cell pairs showed robust synchrony during all directions of stimulus movement, with the exception of the null direction. Null stimulus movement evoked a GABAergic inhibition, resulting in a temporal shift in the firing pattern of neighboring ON DS cells and desynchronization of spike activity. We propose that, in addition to reduced spike activity, ON DS cells encode stimulus movement in the null direction by an active desynchronization of neighbors that will reduce summation of convergent inputs to neurons in the AOS.

\section{Materials and Methods}

Flattened retina-sclera preparation. The animal preparation used in this study has been described previously (Hu et al., 2000). Briefly, adult New Zealand White rabbits (Oryctolagus cuniculus) were anesthetized with an intraperitoneal injection of $40 \%$ ethyl carbamate $(2.0 \mathrm{~g} / \mathrm{kg}$ body weight) and a local injection of $2 \%$ lidocaine hydrochloride to the eyelids and surrounding tissue. The eye was then removed under dim red illumination and hemisected $\sim 1 \mathrm{~mm}$ posterior to the ora serrata. The vitreous humor was removed with ophthalmic sponges, and the resultant retina eyecup was flattened by making radial cuts at the periphery in a Maltesecross configuration. The retina eyecup was then placed in a superfusion chamber, which was mounted on the stage of an upright light microscope (BX51 WI; Olympus Optical, Tokyo, Japan) within a light-tight Faraday cage. The eyecup was superfused at a rate of $30 \mathrm{ml} / \mathrm{min}$ with a mammalian Ringer's solution containing the following (in mM): $120.0 \mathrm{NaCl}, 5.0$ $\mathrm{KCl}, 25.0 \mathrm{NaHCO}_{3}, 0.8 \mathrm{Na}_{2} \mathrm{HPO}_{4}, 0.1 \mathrm{NaH}_{2} \mathrm{PO}_{4}, 10.0$ glucose, 0.01 ascorbate, $1.0 \mathrm{MgSO}_{4}$, and $2.0 \mathrm{CaCl}_{2}$. The superfusate was kept at a constant temperature of $34^{\circ} \mathrm{C}$, with oxygenation and $\mathrm{pH} 7.4$ maintained by bubbling with a gaseous mixture of $95 \% \mathrm{O}_{2}-5 \% \mathrm{CO}_{2}$. After enucleations, animals were killed with an intracardial injection of ethyl carbamate. All animal procedures were in compliance with the National Institutes of Health's Guide for the Care and Use of Laboratory Animals and approved by the Institutional Animal Care and Use Committee at New York University School of Medicine.

To visualize cells for recording, three to five drops of $0.1 \%$ Azure B were applied to the retina to label cells in the ganglion cell layer (GCL). A $900 \mathrm{~nm}$ cutoff filter allowed transmission of infrared (IR) light from below the stage and then up through a condenser and the glass coverslip mounted in the superfusion chamber. An IR-sensitive CCD camera (VE1000; Dage-MTI, Michigan City, IN) captured the retinal image that was displayed on a video monitor outside the Faraday cage. This paradigm allowed retinas to remain in the dark-adapted state during viewing.

Electrophysiology. Intracellular recordings were obtained from neurons using an Axoprobe amplifier (Molecular Devices, Union City, CA). Electrodes were filled at their tips with $4 \% \mathrm{~N}$-(2-amino-ethyl)biotinamide hydrochloride (Neurobiotin; Vector Laboratories, Burlingame, $\mathrm{CA}$ ) in $0.1 \mathrm{~m}$ Tris buffer, $\mathrm{pH} 7.4$, and then back-filled with $4 \mathrm{M} \mathrm{KCl}$. Final DC resistances of these electrodes ranged from 350 to $450 \mathrm{M} \Omega$. After physiological characterization of a cell, Neurobiotin was injected into the cell, with a combination of sinusoidal $(3 \mathrm{~Hz} ; 0.4 \mathrm{nA}$; peak-topeak) and DC current (0.4 nA) applied simultaneously. This method allowed for passage of tracer through the microelectrode without polarization. All injections were made in and around the visual streak region corresponding to $1.0-3.2 \mathrm{~mm}$ from the visual streak.

Single and dual extracellular recordings were obtained from neurons using carbon fiber microelectrodes (World Precision Instruments) attached to an isolated AC differential amplifier (DAM80i; World Precision Instruments, Sarasota, FL). It should be noted that the carbon electrodes effectively recorded activity from cells only when placed directly atop their somata. Thus, there was no ambiguity in identification of the cell being recorded.

For pharmacological experiments, drugs were applied to the retina by switching from the control Ringer's solution to one containing either 50 $\mu \mathrm{M}$ picrotoxin (PTX) or $25 \mu \mathrm{M} 18 \beta$-glycyrrhetinic acid (18 $\beta$-GA) (Sigma, St. Louis, MO). All recording data were digitized on-line with an analog-to-digital board (Digidata 1200; Molecular Devices) and stored for off-line analyses.

Light stimulation. Light intensity of visual stimuli was measured using a portable photometer/radiometer (Ealing Electro-Optics, Holliston, MA). Intensities are expressed as the time-averaged rate of photoisomerizations per rod $\left(\mathrm{Rh}^{*} \operatorname{rod}^{-1} \mathrm{~s}^{-1}\right)$. For these calculations, it was necessary to calculate the effective collecting area of a rod at the peak absorption wavelength. Rod outer segments in the rabbit retina are typically $11 \mu \mathrm{m}$ long and $1 \mu \mathrm{m}$ in diameter (Prince and McConnell, 1964). Taking a specific axial density of rhodopsin of $0.015 \mu \mathrm{m}^{-1}$ and a quantum efficiency of photoisomerization of 0.67 (Liebman and Entine, 1964; Dartnell, 1968), the effective collecting area (ECA) can be calculated by the following equation: $\mathrm{ECA}=\pi\left(0.5 \mu \mathrm{m}^{2}\right) \times 0.67 \times\left(1-10^{-0.015 \times 11}\right)=$ $0.17 \mu \mathrm{m}^{2}$. Thus, 5.8 photons $\mu \mathrm{m}^{-2} \mathrm{~s}^{-1}$ was approximately equivalent to $1 \mathrm{Rh}^{\star} \operatorname{rod}^{-1} \mathrm{~s}^{-1}$. The ECA was reduced by 0.8 and $1.0 \%$ to account for the lower absorption of the 468 and $480 \mathrm{~nm}$ test stimuli from the peak of $502 \mathrm{~nm}$ based on the Dartnell nomogram for the rod spectral sensitivity in the rabbit (Dodt and Elenius, 1960; Nuboer, 1971; DeMonasterio, 1978).

Because changes in adaptational state can influence neuronal coupling (Mangel and Dowling, 1985; Bloomfield et al., 1997; Xin and Bloomfield, 1999), light stimulus intensities were kept within the scotopic range and retinas were maintained in a dark-adapted state. For initial surveys of the light-evoked responses of cells, a green light-emitting diode $\left(\lambda_{\max }=468\right.$ $\mathrm{nm}$ ) focused onto the retinal surface provided full-field illumination in the low scotopic intensity range $\left(4.7 \mathrm{Rh}^{\star} \operatorname{rod}^{-1} \mathrm{~s}^{-1}\right)$. To test direction selectivity, a $50-\mu \mathrm{m}$-wide rectangular slit of light was projected onto the retina using a $100 \mathrm{~W}$ halogen lamp in a Newtonian light bench with a narrowband chromatic filter $\left(\lambda_{\max }=480 \mathrm{~nm}\right)$. The intensities of these stimuli were also kept within the scotopic range $\left(2.5-10.0 \mathrm{Rh}^{*} \operatorname{rod}^{-1}\right.$ $\left.\mathrm{s}^{-1}\right)$. The slit was swept back and forth across the retinal surface at four orientations, $0,45,90$, or $135^{\circ}$, where $90^{\circ}$ corresponded to the orientation of the visual streak. The slit speed ranged from $\sim 90$ to $180 \mu \mathrm{m} / \mathrm{s}$. To measure receptive field size, a $50-\mu \mathrm{m}$-wide/ $300-\mu \mathrm{m}$-long rectangular slit of light was moved along its minor axis in discrete steps (as small as $3 \mu \mathrm{m}$ ) in both directions from a position centered on the soma of a cell. The slit was oriented either parallel or orthogonal to the visual streak so that cells' receptive fields were calculated along two orthogonal orientations. The intensity of the slit was $2.5-10 \mathrm{Rh}^{\star} \operatorname{rod}^{-1} \mathrm{~s}^{-1}$.

Analysis of spike activity. Spikes were sorted and time-stamped off-line using commercially available software (Off-Line Sorter;Plexon, Dallas, TX). Cross-correlation functions between pairwise spike trains were computed by histogramming all time differences between spikes recorded from one cell and those from the neighboring cell (NeuroExplorer software; Plexon). Significance of correlations above chance was determined by computing the $99 \%$ confidence limits.

For light-evoked spiking, a shift predictor correction procedure separated the features of the cross-correlation functions resulting from the coactivation of cells by the light stimulus. The shift predictor was generated in the same manner as a normal cross-correlation function except that one of the spike trains was shifted over one or more stimulus intervals. Here, the shift predictor was created as the arithmetical mean of all possible interval shifts. The shift predictor was then subtracted from the original cross-correlation function to generate the shift-predicted function, which included only those correlations independent of the light stimulus.

A selectivity ratio was computed for ON DS ganglion cells by averaging the spikes in a $1 \mathrm{~s}$ bin for 10 sweeps in one direction and then in the opposite direction. The ratio was then taken as the quotient of the two averages. Onset spike latencies were computed as the time between stimulus onset and the first spike in the light-evoked firing train. Averages of latencies were computed from sampling 10 light-evoked responses. Differences in the spike onset latencies of cell pairs recorded simultaneously were then calculated from the average values. It should be noted that, because ON DS ganglion cells showed little spontaneous activity, lightevoked activity was easily differentiated from background firing.

Histology. After electrophysiological experiments, retinas were fixed in a cold $\left(4^{\circ} \mathrm{C}\right)$ fixative solution of $4 \%$ paraformaldehyde $-0.1 \%$ gluteraldehyde in $0.1 \mathrm{~m}$ phosphate buffer, $\mathrm{pH} 7.3$, for $12 \mathrm{~min}$. The retina was then detached, trimmed, fixed onto a gelatinized glass coverslip, and left in fixative overnight at $4^{\circ} \mathrm{C}$. Retinas were washed for $4-5 \mathrm{~h}$ in $10 \mathrm{~mm}$ sodium PBS (9\% saline; pH 7.6) and then reacted with the Elite ABC kit (Vector 
Laboratories) and 1\% Triton X-100 (Sigma) in PBS overnight at $4^{\circ} \mathrm{C}$. Retinas were processed for peroxidase histochemistry using 3-3' diaminobenzidine (DAB) with cobalt intensification, dehydrated, cleared, and flat-mounted in Permount (Fisher Scientific, Houston, TX).

To determine the level at which dendritic processes stratified in the inner plexiform layer (IPL), we examined Neurobiotin-labeled cells in flat-mount under a $100 \times$ objective. The borders of the IPL were determined by the location of amacrine and ganglion cell bodies using differential interference contrast optics. The position of the outer margin of the IPL was defined as 100 . The position of cellular processes in the IPL was determined using a precision micrometer and given a value from 1 at the innermost margin to 100 at the outermost. Multiple measures were made for a single cell to elucidate any variations in stratification throughout its extent.

\section{Results}

\section{Morphology of crescent ganglion cells}

To target ganglion cells for recordings and injections, we used a recently developed, flattened retina-sclera preparation in which neurons in the GCL can be visualized under IR illumination ( $\mathrm{Hu}$ et al., 2000). After labeling with the vital dye Azure B, a heterogeneous population of cell bodies was discernible, evidenced by a wide variation in soma shapes, sizes, and labeling intensities (Fig. 1A). However, cell bodies with similar morphology often formed regular mosaics indicative of single cell subtypes, which included the large somata of $\alpha$ ganglion cells. Another mosaic was formed by a group of cells with smaller somata, $\sim 15 \mu \mathrm{m}$ in diameter, which had a crescent-shaped appearance after Azure B labeling (Fig. $1 A, B$ ). Although seen throughout the retina, these crescent cells lay mainly within and near the visual streak region where cell density is highest. In this region, these cells formed a regular array with nearest neighbor distances ranging from $\sim 50$ to $250 \mu \mathrm{m}$ with an average of $150 \mu \mathrm{m}$ (Fig. $1 C$ ). The regular array formed by the crescent cells suggested that they formed a single subtype of ganglion cell (Wässle and Reimann, 1978).

To identify the soma-dendritic morphology and coupling pattern of the crescent cells, we injected their somata with the gap junction-permeant tracer Neurobiotin through an intracellular micropipette. All injected crescent cells $(n=17)$ showed a stereotypic morphology consisting of a densely branched dendritic arbor formed by wavy processes that monostratified within the proximal portion (sublamina $b$ ) of the IPL (Fig. $1 D, E)$. The arbor displayed short terminal branches that occasionally curled back in the direction of the soma. Crescent cells also showed a prominent axon that ran to the optic disc, thus identifying them as ganglion cells. Crescent cells that lay within the visual streak showed more asymmetry in their dendritic architecture than those found more peripherally (Fig. $1 D, E$ ). After reviewing previous studies, we found that the soma-dendritic morphology of crescent cells very closely matched that described for the ON DS ganglion cells found in the rabbit retina that project to the AOS (Buhl and Peichl, 1986; Amthor et al., 1989; Pu and Amthor, 1990; He and Masland, 1998). Because we injected cells mainly within the visual streak region, the crescent cells we labeled showed the characteristic morphology of centrally located ON DS cells, which included more asymmetry and dendritric undulations than those found more peripherally. These differences mirror those reported for central versus peripheral ON DS cells in the rabbit retina (Buhl and Peichl, 1986; Pu and Amthor, 1990).

\section{Tracer-coupled amacrine cells}

The crescent cells were tracer coupled to a dense array of small, round cell bodies, $<10 \mu \mathrm{m}$ in diameter, which emitted branches that could be followed for up to $1 \mathrm{~mm}$ before gradually fading
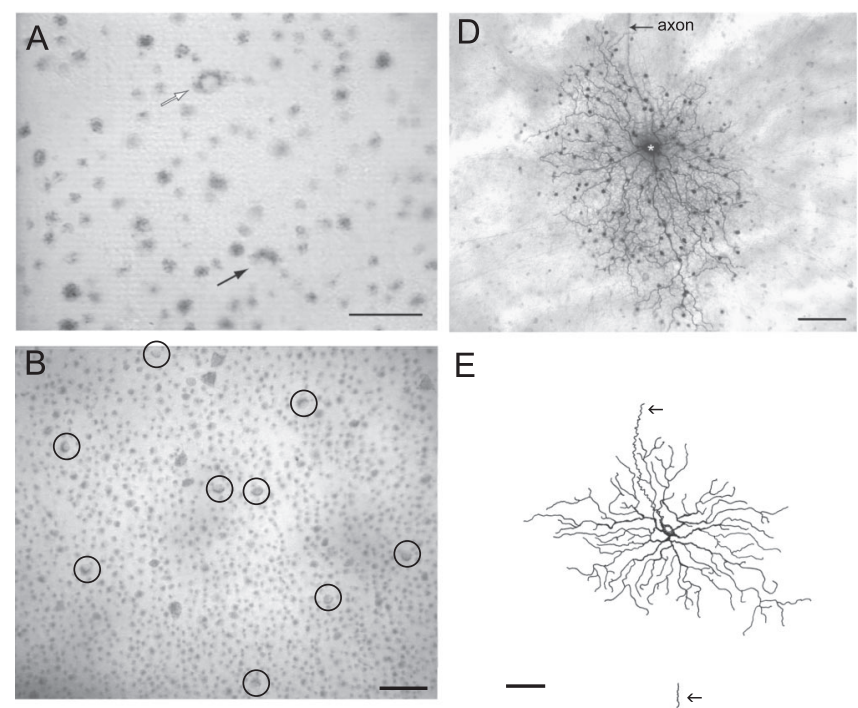

E
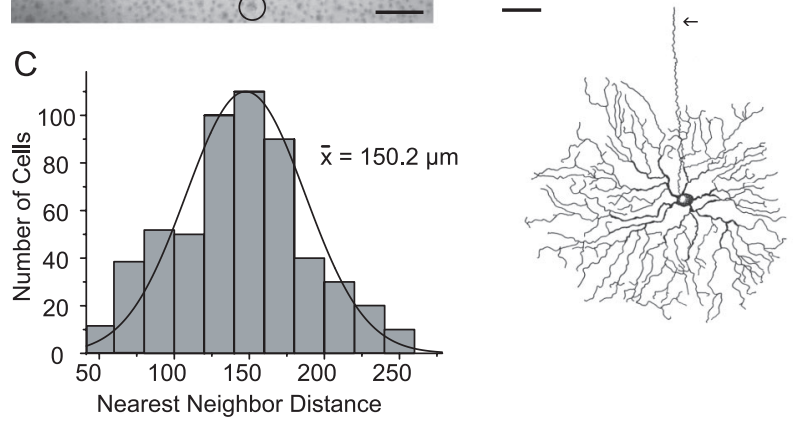

Figure 1. Crescent-shaped ganglion cells form a regular mosaic that can be easily targeted for recording and labeling. $\boldsymbol{A}$, Digital video image of the living flattened retinal-scleral preparation during an experiment. Ganglion cells with relatively large somata are easily visualized after Azure B labeling, including the $\alpha$ cells (open arrow). The crescent-shaped cells can be easily identified by their characteristic labeling pattern (closed arrow). Scale bar, $50 \mu \mathrm{m}$. $\boldsymbol{B}$, Digital video image showing an array of crescent ganglion cells (circled) in the visual streak region. Scale bar, $50 \mu \mathrm{m}$. C, Histogram of nearest-neighbor distances between the somata of crescent ganglion cells within the visual streak region. The solid line is a Gaussian fit to the data. The average distance between crescent cells in the visual streak was $150 \mu \mathrm{m}$. D, Photomicrograph showing the complete morphology of a crescent cell labeled with Neurobiotin at an eccentricity of $1.8 \mathrm{~mm}$ from the optic disk. This cell shows a stereotypic asymmetric dendritic field and coupling to an array of amacrine cells that exhibit relatively small somata. Long axonlike processes of the amacrine cells can be seen extending beyond the field of view. Scale bar, 50 $\mu \mathrm{m}$. $\boldsymbol{E}$, Camera lucida drawings of Neurobiotin-labeled crescent cells showing variation in morphology with eccentricity. Cell eccentricities were 2.2 and $3.2 \mathrm{~mm}$, respectively, from the optic disk. The arrows indicate an axon. Scale bar, $50 \mu \mathrm{m}$.

from view (Figs. 1D, 2B). On closer inspection of several well labeled amacrine cells, it became apparent that they displayed two distinct systems of processes characteristic of polyaxonal cells (Dacey, 1989; Famiglietti, 1992a,b; Völgyi et al., 2001). These included a dendritic field of highly branched and relatively thick processes that terminated proximally (Fig. $2 A-C$ ). The other system was formed by an extensive axonal arbor of multiple thin axons that showed little or no branching (Fig. $2 \mathrm{~A}$ ). Both the dendritic and axonal arbors stratified in the approximate $70-$ $80 \%$ level of the IPL. Unfortunately, these cells did not display a morphology that could be matched to those of the several subtypes of polyaxonal amacrine cells previously described in the rabbit retina (Famiglietti, 1992a,b; Völgyi et al., 2001). Thus, although some polyaxonal cell subtypes show homologous coupling (Völgyi et al., 2001), it remains unclear whether the polyaxonal amacrine cells coupled to crescent ganglion cells are also coupled to each other. 

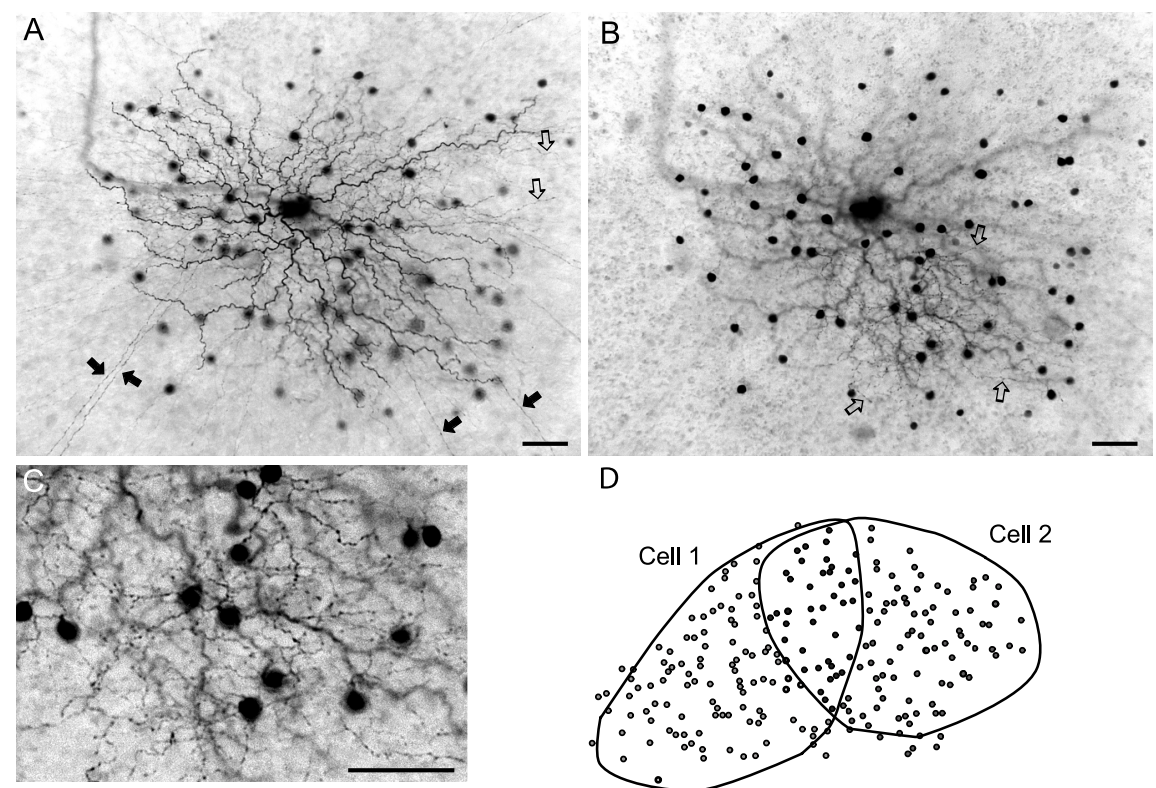

D

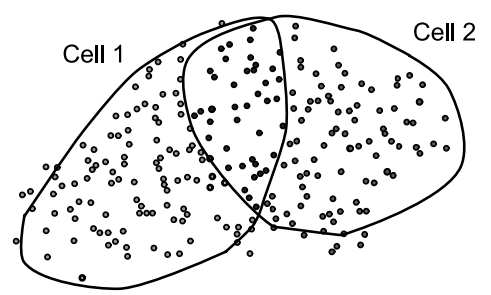

$\mathrm{E}$
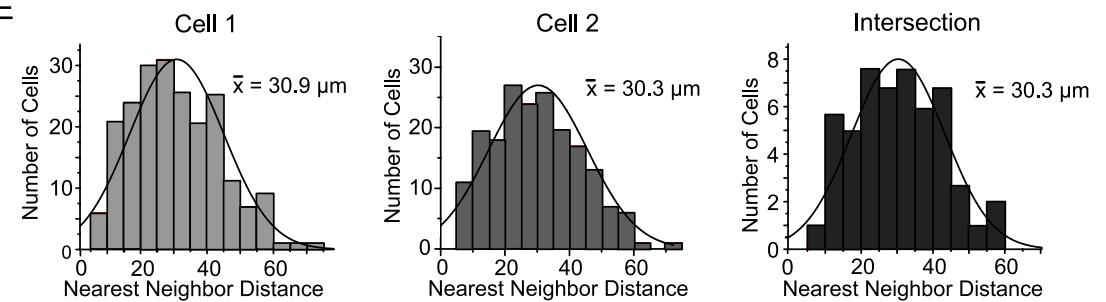

Figure 2. Crescent-shaped ganglion cells are coupled to polyaxonal amacrine cells. $\boldsymbol{A}$, Neurobiotin-labeled crescent ganglion cell and tracer-coupled amacrine cells. Long, straight axon-like processes can be seen extending beyond the field of view (filled arrows). In addition, the amacrine cells maintain more curvy processes that end proximally (open arrows). Scale bar, $25 \mu \mathrm{m}$. $\boldsymbol{B}$, Plane of focus at the distal edge of the IPL, showing the processes emerging from the tracer-coupled amacrine cell somata. These relatively thick, undulating, and varicose processes (open arrows) are quite different from the long axon-like processes illustrated in $\boldsymbol{A}$. These morphological features indicate that the amacrine cells are polyaxonal cells with dendritic and axonal systems. Scale bar, $25 \mu \mathrm{m}$. C, Higher magnification view of amacrine cell dendritic processes illustrated in $\boldsymbol{B}$. Scale bar, $25 \mu \mathrm{m}$. $\boldsymbol{D}$, Schematic showing the outline of the dendritic arbors of two neighboring crescent ganglion cells, each of which was labeled with Neurobiotin. The shaded circles indicate the somata of the tracer-coupled polyaxonal amacrine cells. $\boldsymbol{E}$, Histograms illustrating the nearest-neighbor distributions of the amacrine cell somata laying within the independent dendritic zones of the two ganglion cells and within the intersecting area. The Gaussian curves (solid lines) fit to the three data sets were identical. These data indicate that neighboring crescent ganglion cells are coupled to a common cohort of amacrine cells.

Interestingly, the amacrine cell somata formed an array that closely matched the area occupied by the dendritic arbor of the injected crescent ganglion cell (Figs. $1 B, 2 B$ ). This pattern was a characteristic of all crescent cell injections. It suggests that, whereas gap junctions are found throughout the dendritic arbor of crescent ganglion cells, they occur only proximally within the dendritic arbor system of the coupled polyaxonal amacrine cells.

To determine whether neighboring crescent cells were coupled to the same cohort of polyaxonal cells, nearest-neighbor ganglion cells were labeled with Neurobiotin. Figure $2 D$ shows the outline of the dendritic arbor of two neighboring crescent cells as well as the array of tracer-coupled polyaxonal amacrine cell somata. As shown here, the dendritic arbors of ON DS cells with the same directional preference showed partial overlap. The Gaussian profile of the amacrine cell indicated a regular mosaic characteristic of single subtype of cells in the mammalian retina (Wässle and Reimann, 1978) (Fig. 2E). Moreover, we found that the distribution of amacrine cell somata showed the same nearest-neighbor frequencies within the independent dendritic regions of each cell and in the area of overlap. These data indicate that nearest-neighbor crescent cells are coupled to the same subset of amacrine cells. We saw no evidence of tracercoupled ganglion cells after Neurobiotin injection of a crescent cell, suggesting that crescent cells are coupled only indirectly via the polyaxonal amacrine cells (see below).

\section{Crescent cells are $\mathrm{ON}$ direction selective ganglion cells}

We subsequently conducted electrophysiological experiments to determine the light-evoked physiology of crescent ganglion cells to confirm their identification as ON DS cells. Crescent cells $(n=69)$ responded to full-field illumination with an initial burst of activity at light onset followed by a sustained component; the sustained component was somewhat variable between crescent cells with some showing less sustained activity (Fig. 3A). The light-evoked responses indicated an on-center receptive field physiology for these cells, consistent with their dendritic arborization within sublamina $b$ of the IPL (Nelson et al., 1978; Bloomfield and Miller, 1986). Intracellular records also showed a characteristic, slow rebound hyperpolarization at stimulus offset. To test for direction selectivity, a rectangular slit of light was slowly swept across the retina at a speed of $\sim 180 \mu \mathrm{m} / \mathrm{s}$ along four different axes (Fig. 3B). For this cell, we found a directional preference for stimulus movement along the horizontal axis, characterized by a dramatic increase in impulse activity for temporal to nasal (rightward) movement and only a small, attenuated response for movement in the opposite (null) leftward direction. In contrast, stimulus movement along the orthogonal orientation showed no preference, with equal responses to movement in either direction. We found that all crescent cells showed direction selectivity with an average selectivity ratio of $4.6 \pm 0.5$. The directional preferences of cells were found to lie approximately along three axes-temporal to nasal, upward, and downward-consistent with those reported previously for ON DS cells in the rabbit (Oyster, 1968). As we have shown for other amacrine and ganglion cells in the rabbit retina (Bloomfield, 1992; Bloomfield and Xin, 1997), the receptive field size of individual ON DS cells closely matched the extent of their dendritic arbors. Overall, the morphological and physiological features of crescent cells indicated unequivocally that they were ON DS ganglion cells.

Interestingly, we found that nearest-neighbor ON DS cells tended to have the same directional preference. For example, the schematic in Figure $3 C$ shows the directional preference for a cluster of ON DS ganglion cells. The central cluster of eight cells showed the same temporal-to-nasal direction selectivity, whereas cells at the periphery of the cluster showed different preferences, but still matched that of their closest neighbors. Our results suggest that ON DS ganglion cells with the same directional prefer- 


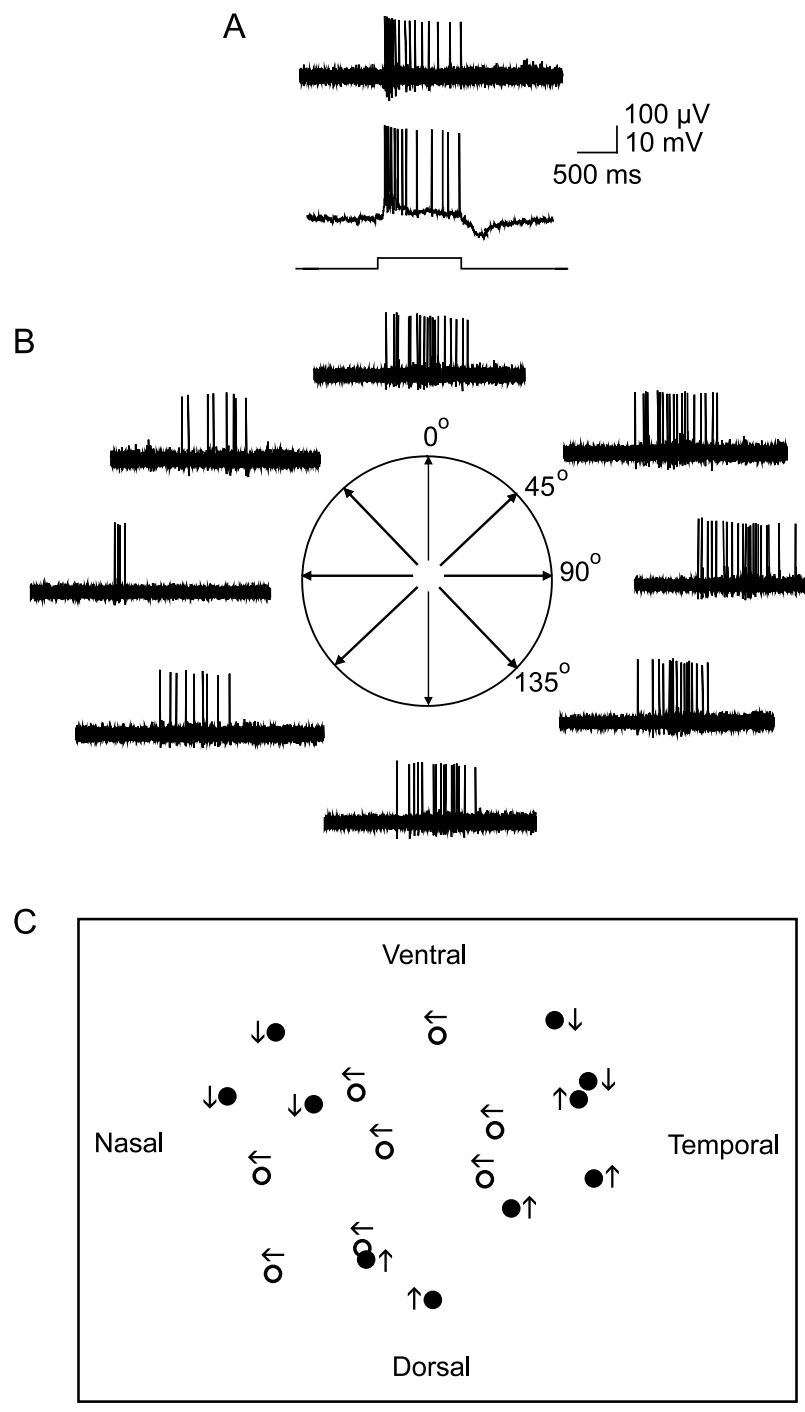

Figure 3. Crescent-shaped ganglion cells are $0 \mathrm{~N}$ direction selective cells. $A$, At the top is a sample extracellular recording from a crescent-shaped ganglion cell. This cell shows a transient burst of spikes at stimulus onset followed by a sustained component during stimulus presentation indicating on-center receptive field physiology. The bar at the bottom indicates onset and offset of full-field stimulus. Below is an intracellular recording from the same crescent-shaped cell showing the evoked spiking and slow potentials. This cell shows a hyperpolarizing component at light offset characteristic of crescent-shaped ganglion cells. $\boldsymbol{B}$, Response of the cell to a $50-\mu \mathrm{m}$-wide slit of light swept back and forth across the retina along four different orientations. The cell is direction selective for temporal to nasal (rightward) movement along the horizontal axis. C, Schematic showing the direction preference for a cluster of ON DS cells. The cells in middle of the cluster (open circles) show the same temporal to nasal preference. Cells at the edges show different preferences (dark circles) but show neighbors with the same preference as well. These data suggest that DS ganglion cells with the same direction preference tend to form overlapping clusters with cells with different preferences.

ence are organized into clusters of $8-15$ cells that partially overlap with neighboring clusters of cells with difference preferences. We found also that the closest ON DS cells, displaying the greatest dendritic overlap, showed different directional preference, indicating that they reflect the overlapping borders of neighboring cell clusters (Fig. 3C). This organization is similar to that suggested by Vaney (1991) for ON-OFF DS ganglion cells.

Synchronous activity of neighboring ON DS ganglion cells As mentioned above, a number of studies have shown that gap junctions underlie the concerted activity between ganglion cells, and so we performed simultaneous recordings from pairs of nearest-neighbor ON DS cells $(n=12)$ (Fig. $4 A)$. In these experiments, simultaneous recordings were made from neighboring DS cells that showed the same directional preference. Initial studies focused on correlations between spontaneous spike activity. Because ON DS cells show relatively low spontaneous activity (Oyster, 1968), simultaneous recordings from cell pairs were performed for up to $3 \mathrm{~h}$ to accumulate sufficient numbers of spikes ranging from $\sim 2000$ to 4000 . Cross-correlograms of paired, spontaneous activity showed a narrow profile (half-width, 6.3 $\mathrm{ms}$ ) with a single peak centered at time 0 , indicative of strong synchronization (Fig. $4 B$ ). This narrow profile reflected the finding that $50.6 \pm 4.6 \%$ (average $\pm \mathrm{SE}$ ) of spikes evoked spontaneously by pairwise-recorded neighboring cells were synchronous (defined as having latency of $0 \pm 3 \mathrm{~ms}$ ). Overall, we found that all nearest neighbor and $\sim 80 \%$ of second-tier ON DS cells (with same directional preference) showed spontaneous spike synchrony, whereas third-tier neighbors did not.

The cross-correlation functions for spikes evoked with fullfield pulses of light also displayed a single peak at time 0 , but with a broader function (half-width, $22.0 \mathrm{~ms}$ ) than that seen for spontaneous activity (Fig. 4 C). Still, an average $50.1 \pm 2.6 \%$ of spikes were synchronous. We used a shift-predictor analysis to shuffle the data and thereby remove all correlations between cell pairs attributable to common inputs synched to the light stimulus. The resultant cross-correlogram, which revealed synchrony independent of the light stimulation, showed a narrow function with a peak at time 0 , very similar to that seen for spontaneous spiking of cell pairs (Fig. 4D). After application of the shift predictor, an average $51.3 \pm 4.8 \%$ of evoked spikes were synchronous. These data indicate that the correlation of light-evoked spikes includes two components: a relatively broad, light-dependent correlation and a narrow profile reflecting synchrony that is independent of the light stimulus.

We next examined how the directionality of moving light stimuli affected the concerted activity of ON DS cell pairs $(n=$ 12). We found that stimulus movement in the preferred direction evoked robust spiking in cell pairs that was highly synchronized (Fig. 5A). Cross-correlograms of spiking evoked by preferred stimulation consisted of a broad profile shifted from time 0 because of the fact that the moving light stimulus encountered the receptive field of one cell before the other (Fig. 5B). Moreover, the functions showed a prominent peak at time 0 corresponding to the strong spike synchrony. Despite the broad function produced by the slowly moving stimulus, we found that an average of $22.2 \pm 3.5 \%$ of all evoked spikes were synchronous. In contrast, stimulus movement in the null direction evoked only weak activity, but the cross-correlograms still showed the broad correlations attributable to the light, albeit with fewer spikes (Fig. 5C). However, the prominent peak at time 0 seen in the crosscorrelograms for preferred stimulation was absent in the null direction, reflecting a dramatic reduction in spike synchrony (Fig. $5 D$ ). Only $2.9 \pm 0.5 \%$ of evoked spikes were synchronous during null direction movement, an $87 \%$ reduction in synchrony from preferred stimulation levels.

Preferred and null direction stimulation also produced clear differences in the spike onset latencies of ON DS cells. For preferred stimulation, we observed a relatively short onset latency difference between the responses of the simultaneously recorded cell pairs (average, $27.2 \pm 6.1 \mathrm{~ms}$ ). In contrast, movement in the null direction brought about a nearly sevenfold increase (average, $165.0 \pm 47.8 \mathrm{~ms}$ ) in the latency between the response onset of ON DS pairs. This latency shift was also apparent 
A

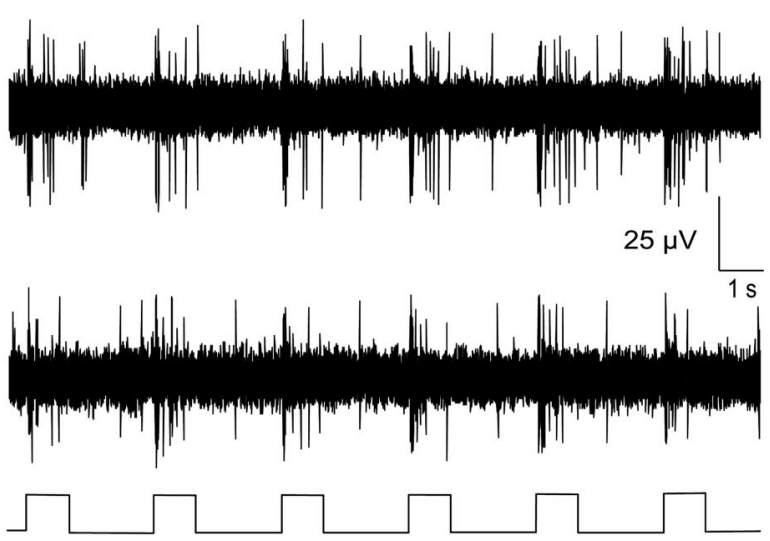

B

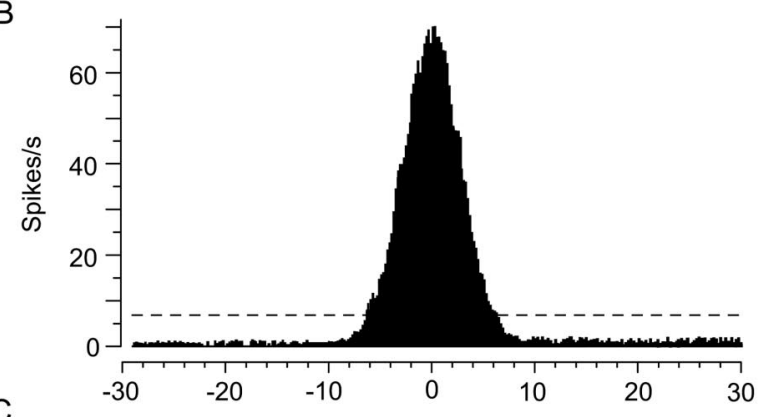

C
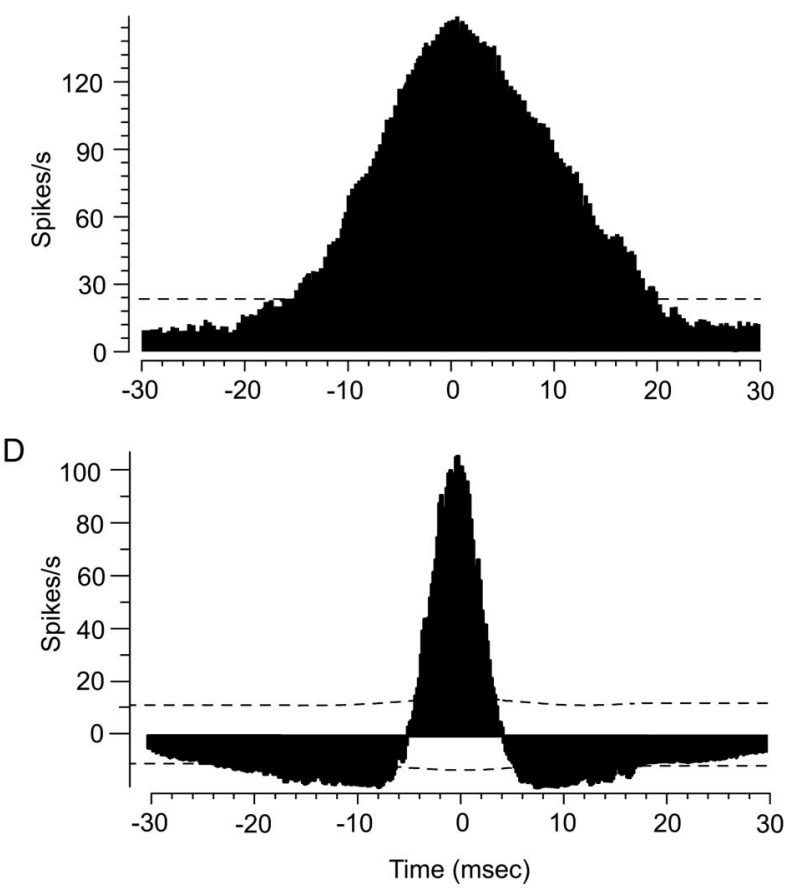

Figure 4. Cross-correlation functions for spontaneous and light-evoked spiking of neighboring ON DS ganglion cells. $A$, Light-evoked responses of two ON DS ganglion cells recorded simultaneously. The trace at the bottom of the panel indicates the onset and offset of the full-field stimuli. $\boldsymbol{B}$, Crosscorrelogram of the spontaneous activity between a neighboring pair of ON DS cells recorded simultaneously. Distribution shows a narrow profile with peak at time 0 . The dashed line is the $99 \%$ confidence limit. C, Cross-correlogram of the light-evoked spikes of the same cell pair in response to a stationary full-field stimulus. Distribution also shows a single peak at time 0 , but is broader than that for spontaneous spikes. D, Shift predictor analysis of the light-evoked spikes shown in C eliminates correlations attributable to the light stimulus. After analysis, the profile still maintains a single peak at time 0 , but is narrower, closely matching the cross-correlogram for spontaneous spikes. These data suggest that light-evoked concerted spiking is reflected by the broader profile component, whereas light-independent spike synchrony is reflected by the narrow component. when comparing the cross-correlogram functions for preferred and null stimulation as a shift in the peak of the broad component (Fig. $5 B, D$ ).

Our results indicated a clear difference between preferred and null direction stimulation in terms of spike synchrony and onset latency of ON DS cell pairs. To determine whether these effects were restricted to movement along the preferred/null (selective) axis, we extended our analysis to stimulus movement along the orthogonal axis for which ON DS cells were not direction selective $(n=12)$. The cross-correlograms for the spikes evoked by stimulus movement along the nonselective axis were essentially mirror images, reflecting the opposite direction movement of the slit (Fig. 6). Both consisted of identical broad correlations attributable to the light stimulus and a prominent peak at time 0 , indicating that spike synchrony was unaffected by the direction of stimulus movement. We also found no difference in the onset latencies of spiking induced by the two directions of stimulus movement along the nonselective axis (average difference of $0.0 \pm 0.1 \%)$. Interestingly, the average onset latency difference for responses to stimulus movement along the nonselective axis was very similar to that found for movement in the preferred direction (average difference of $3.2 \pm 0.2 \%$ ). Together, these data indicate that stimulus movement in the null direction uniquely produces a large shift in onset latency between neighboring ON DS cells and a loss of spike synchrony.

\section{GABAergic inhibition underlies the latency shift and desynchronization produced by null stimulation}

A GABAergic inhibition induced by null stimulation is thought to underlie the direction selectivity of DS cells (Caldwell et al., 1978; Kittila and Massey, 1997). We therefore determined whether this inhibition is also involved in the onset latency shift and desynchronization brought about by stimulus movement in the null direction. As reported previously (Caldwell et al., 1978; Kittila and Massey, 1997), application of the nonselective GABA receptor blocker PTX $(50 \mu \mathrm{M})$ increased the light-evoked and spontaneous activity of ON DS cells and abolished their direction selectivity $(n=10)$ (Fig. 7A-C). Moreover, PTX eliminated the latency shift normally produced by stimulus movement in the null direction, resulting in equivalent onset latencies in response to both preferred and null stimulation (Fig. 7D). Application of PTX also restored the synchronized spiking of ON DS cell pairs during null stimulation, as reflected in the emergence of a sharp peak at time 0 in the cross-correlogram (Fig. 7E). The PTX produced a large increase in evoked spiking (note difference in the ordinate axes of panels in Fig. 7E). Thus, the peak at time 0 is very large, but obscured by the increased asynchronous activity. Together, these results indicate clearly that GABAergic inhibition associated with stimulus movement in the null direction underlies the attenuated response, onset latency shift, and desynchronized firing between neighboring ON DS cells.

\section{Gap junctional coupling underlies synchronization of ON DS} cell pairs

In a final set of experiments, we determined whether the gap junctional coupling between ON DS and wide-field amacrine cells is responsible for the synchronization of light-evoked and spontaneous spiking of ON DS cell pairs. We used $18 \beta$-GA ( 25 $\mu \mathrm{M})$ to disrupt the gap junctions (Davidson and Baumgarten, 1988). Application of $18 \beta$-GA effectively abolished spike synchrony in response to stimulus movement in the preferred direction, as evidenced by a near-complete loss of the peak at time 0 in the cross-correlogram $(n=4)$ (Fig. $8 A)$. However, the broad 
correlation profile was unaffected. The gap junction blocker also eliminated spike synchrony in response to stationary, full-field illumination. This was reflected in a complete loss of all concerted activity in the cross-correlogram after applying a shift predictor function to eliminate correlations attributable to the light stimulus (Fig. $8 \mathrm{~B}$ ). These data are consistent with the idea that the electrical coupling is responsible for the synchronized spike activity between ON DS cells. Furthermore, our finding of spike synchrony between most second-tier ON DS cell neighbors, which showed no dendritic overlap, supports our earlier conclusion based on Neurobiotin labeling coupling patterns that ON DS cells are coupled only indirectly via the polyaxonal amacrine cells.

\section{Discussion}

We found that neighboring ON DS ganglion cells showed both correlated and synchronous activity in response to moving and stationary light stimuli. The correlated activity, reflected as a broad profile in the cross-correlogram, was unaffected by disruption of gap junctions with $18 \beta$-GA, suggesting that it results from common inputs derived from the conventional excitatory chemical synapses made with bipolar cells. In contrast, application of $18 \beta$-GA mostly eliminated synchronous spiking between ON DS cell neighbors, indicating that it is attributable to electrical coupling. Previous studies have reported spike synchrony on a similar time scale and reflected in cross-correlograms with single peaks at time 0 for neighboring ganglion cells in cat and salamander retinas (Mastronarde, 1983; Brivanlou et al., 1998). Moreover, this type of synchrony is believed to be the result of shared excitation through coupling to common amacrine cells, which is fully supported by our finding that ON DS ganglion cells are coupled indirectly via a subtype of wide-field amacrine cell. In this scheme, depolarizing current from the amacrine cell invades neighboring ganglion cells through gap junctions and thereby evokes synched spike activity. The depolarizing current could take the form of spike bursts that directly generate spiking in ON DS cells and/or subthreshold oscillations (Solessio et al., 2002; Petit-Jacques et al., 2005) that synchronize the spikes in ON DS cell neighbors arising from common excitatory inputs from bipolar cells. Our finding that neighboring ON DS cells were coupled to a common large subset of polyaxonal cells suggests that a relatively large number of amacrine cells drive DS cell synchrony. It remains unclear, however, whether the polyaxonal amacrine cells are homologously coupled to each other as well or whether their activity is synchronized. In any event, up to $50 \%$ of light-evoked spiking in ON DS cell pairs were synchronous, suggesting that a significant portion of the excitatory drive to DS ganglion cells is derived from electrical synapses made with amacrine cells in addition to the chemical inputs from bipolar cells; this is consistent with findings from other ganglion cell types (Meister et al., 1995; Brivanlou et al., 1998).
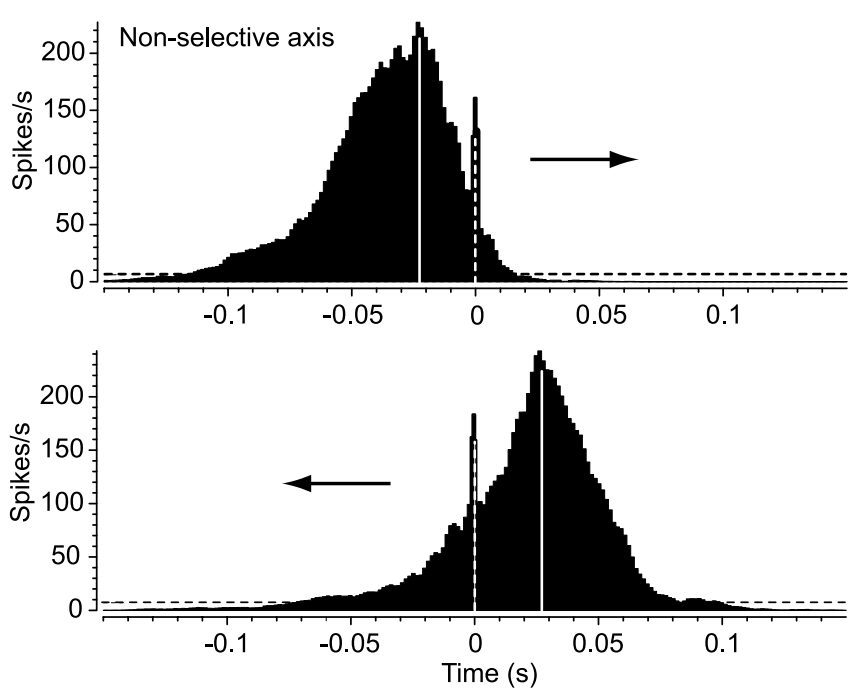

Figure 6. Spike synchrony and spike onset latency are not affected by direction of stimulus movement along the nonselective axis. Cross-correlograms for spiking of neighboring pair of $\mathrm{ON}$ DS cells to the back-and-forth movement of the slit of light along the nonselective axis (orthogonal to the preferred/null axis). In contrast to slit movement along the preferred/null axis, the direction of movement along the orthogonal axis did not affect spike synchrony, as indicated by no change in the peak at time 0 (dashed white line).

\section{Synchrony is modulated by GABAergic null inhibition}

Perhaps the most interesting finding of our study was that the degree of spike synchrony between neighboring ON DS cells was dramatically affected by the direction of stimulus movement. Spike synchrony occurred for all directions of stimulus movement, along both selective and nonselective axes, with the excep- 
A

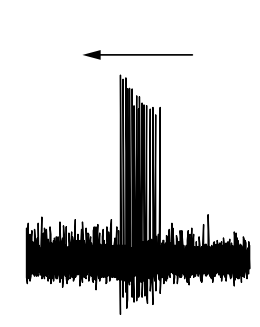

B

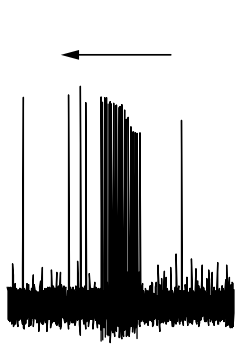

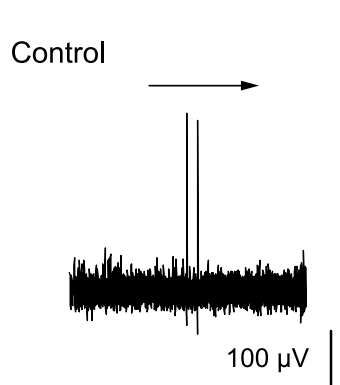

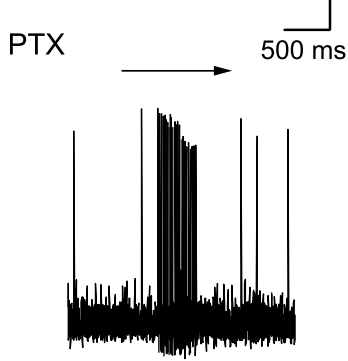

C

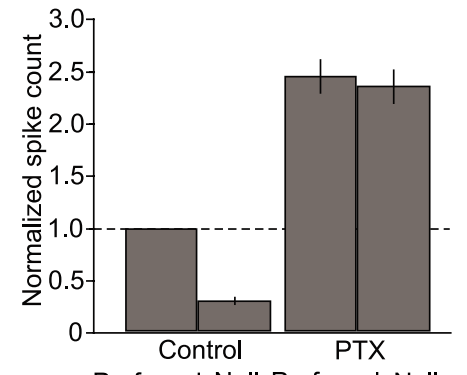

D $\widehat{\text { P }}$ Preferred Null Preferred Null

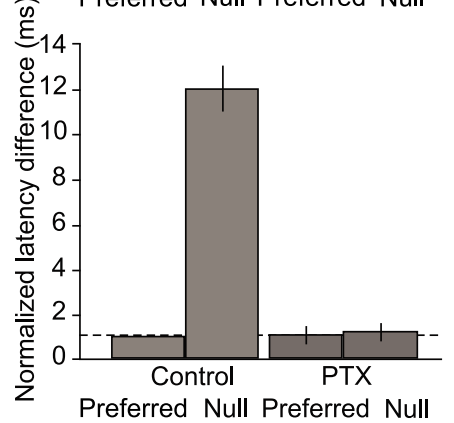

E
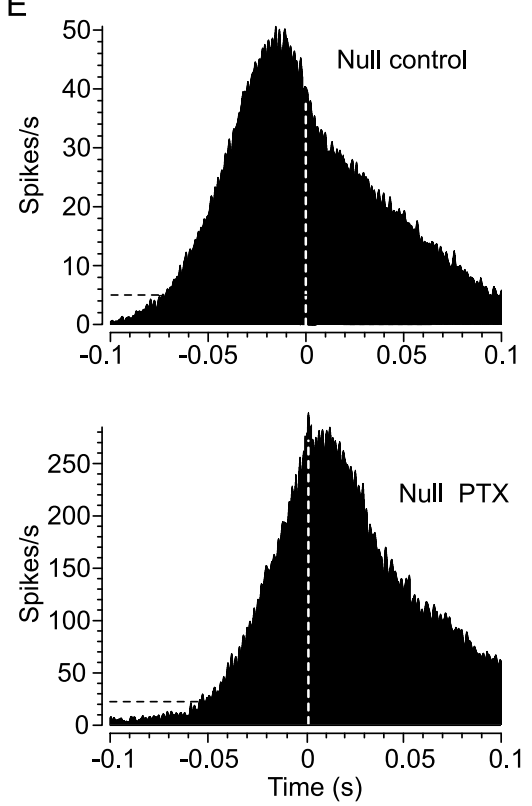

Figure 7. GABAergic inhibition underlies the increased spike onset latency and desynchronization associated with stimulus movement in the null direction. $A$, Extracellularly recorded response of an ON DS cell to slit movement in the preferred and null directions. B, Application of $50 \mu \mathrm{M}$ PTX increases the firing rate of the ON DS cell and abolishes its direction selectivity. C, Histogram comparing average normalized spike count in response to stimulus movement in the preferred and null directions before and after application of PTX. Data are from 10 cell pairs. PTX clearly abolishes direction selectivity. The vertical lines indicate SE. D, Histogram comparing the spike onset latency difference in response to preferred and null direction slit movement before and after PTX application. Under control conditions, null stimulation brings about a $\sim 12$-fold increase in onset latency difference in comparison with that for preferred stimulus movement. Application of PTX abolishes this increase, thereby equalizing the onset latency difference in responses to both preferred and null stimulation. $E$, Cross-correlogram for light-evoked spikes of ON DS cell pair in response to slit movement in the null direction under control conditions (top). There is minimal spike synchrony, as evidenced by the lack of a prominent peak at time 0 (dashed white line). However, application of PTX increases synchrony, as evidenced by the peak at time 0 (bottom). Application of PTX caused an increase in firing; note the different scale of the ordinate axes in the top and bottom panels.
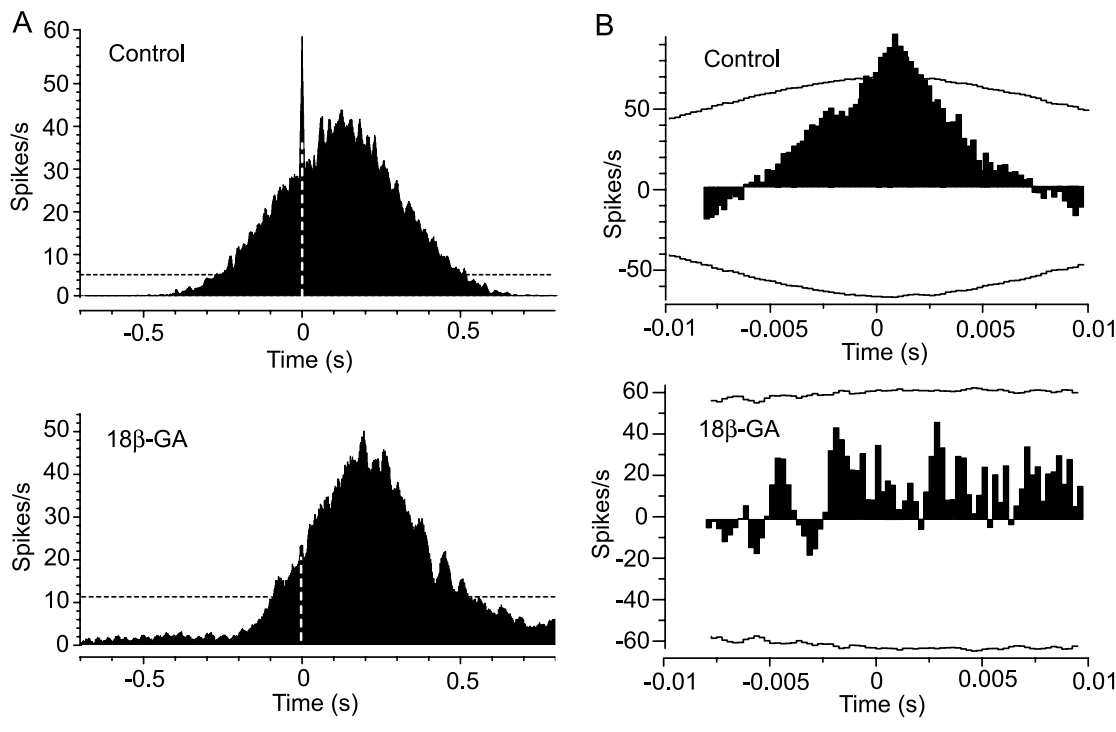

Figure 8. Disruption of gap junctions reduces spike synchrony between ON DS cell pairs. A, At the top is a cross-correlogram of light-evoked spikes of a pair of neighboring ON DS cells in response to slit movement in the preferred direction. Spike synchrony is indicated by the prominent peak at time 0 (dashed white line). Disruption of gap junctions by application of $25 \mu \mathrm{M} 18 \beta$-GA abolishes the peak at time 0 , indicating a desynchronization of cell spiking (bottom). The dashed black line is the $99 \%$ confidence interval. $\boldsymbol{B}$, At the top is a cross-correlogram of the light-evoked spikes of an ON DS cell pair to full-field illumination after a shift predictor analysis. The horizontal curved lines indicate the $99 \%$ confidence limit. The peak at time 0 indicates spike synchrony independent of the light stimulus. At the bottom is the cross-correlogram generated after application of $18 \beta$-GA. Spike synchrony is eliminated by disruption of the gap junctions.

tion of null direction movement. Null stimulation produced a unique and dramatic desynchronization of activity. Previous studies have shown that light-induced changes in adaptational state can globally modulate the coupling between retinal neurons
(Mangel and Dowling, 1985; Bloomfield et al., 1997; Xin and Bloomfield, 1999). The present findings now show that specific light stimulation can also effectively modulate the coupling between neurons to alter their response activity.

The speed at which synchrony was modulated in our experimental situation, in which the light stimulus was continuously swept back and forth across the retina, makes it virtually impossible that this reflected a direct modulation of the gap junctional conductance. Instead, our results indicate that a GABAergic inhibition evoked by null stimulation produced not only the attenuation of firing, but also a temporal shift in activity as reflected in the large increase in the onset latency difference and desynchronization between $\mathrm{ON}$ DS cell pairs. A plausible mechanism is that GABAergic synaptic inputs may be juxtaposed on the gap junctions on dendrites and can effectively shunt intercellular currents, thereby producing the shift in onset latency and desynchronization of DS cell pairs. A similar mechanism in which inhibitory chemical synapses "uncouple" cells by short-circuiting the spread of intercellular current has been reported both in the glomeruli of the inferior olive (Lang et al., 1996; Lang, 2002) and the pharyngeal expansion motoneurons in the mollusk Navanex (Spira et al., 1980). 
Strong, converging evidence indicate that the null inhibition to DS ganglion cells is derived from presynaptic starburst amacrine cells. Interestingly, light-evoked calcium increases in starburst cell dendrites, and the presumed resultant GABA release, are largest for stimuli moving centrifugally from the soma (Euler et al., 2002). Thus, individual dendritic branches, which are isolated electrically from one another (Miller and Bloomfield, 1983; Euler et al., 2002), will be differentially excited depending on the direction of stimulus movement across the retina. Recent work indicates that the connections between starburst cells and DS ganglion cells are spatially asymmetric so that dendrites from different starburst cells that "prefer" a particular stimulus direction converge on the same DS cells, thereby providing for their selectivity (Fried et al., 2002, 2005). It is likely that this same GABAergic circuitry derived from starburst cells provides the shunting inhibition resulting in the temporally shifted and desynchronized activity of DS cells in response to null stimulation. However, as the dendrites of the DS ganglion cells, coupled widefield amacrine cells, and starburst amacrine cells all costratify in the IPL (Dong et al., 2004), it remains unclear whether the shunting of gap junctional currents occurs postsynaptically by direct inhibition of ON DS cell dendrites and/or presynaptically on the dendrites of the polyaxonal amacrine cells.

\section{Role of synchrony of ON DS cells}

Spike synchrony and coherence occurs throughout the visual system and has been studied extensively for retinal ganglion cells (Arnett and Spraker, 1981; Mastronarde, 1983; Meister et al., 1995; Brivanlou et al., 1998; DeVries, 1999, Neuenschwander et al., 1999; Singer, 1999; Usrey and Reid, 1999; Hu and Bloomfield, 2003). A number of global functions have been attributed to spike synchrony, including the enhanced saliency of visual signals or increased temporal precision by which retinal signals are reliably transmitted to thalamic and cortical areas (Alonso et al., 1996; Singer et al., 1997; Castelo-Branco et al., 1998; Singer, 1999). It has been posited that synchronous activity between retinal ganglion cells provides additional information to the brain that is multiplexed with the asynchronous signals, thus enabling efficient transmission across the limited capacity of the optic nerve (Meister et al., 1995; Meister and Berry, 1999).

In contrast, the present results suggest a more clearly defined and focused role for synchrony between ON DS ganglion cells, namely, to encode the direction of stimulus motion. In fact, it is not the synchrony, but the desynchronization to stimulus movement in the null direction that appears to be a key component of how ON DS cells signal direction of movement. Based on our findings, we propose the following mechanism and role for desynchronization in encoding visual signals of ON DS cells. Through the indirect coupling of ON DS cells via polyaxonal amacrine cells, neighboring ON DS cells show synchronous spiking. This synchrony occurs for all directions of stimulus motion, with the exception of null stimulation. Motion in the null direction evokes a GABAergic inhibition that induces a temporal shift in firing that effectively abolishes the synchronization of spiking. Although the synaptic ultrastructure of the ganglion cell synaptic innervation of the AOS has yet to be elucidated, physiological data indicate that tens of ON DS ganglion cells converge onto single neurons in the AOS (Soodak and Simpson, 1988; Kogo et al., 1998). Thus, for all non-null movements, including preferred motion, there is a robust, synchronous signal that, we propose, will temporally summate at AOS target cells. In contrast, null stimulation attenuates and desynchronizes the signals, resulting in reduced summation of convergent inputs. This change in syn- chrony will thereby reinforce the differences in the preferred and null signals generated by DS cells as they converge at the AOS. Overall, we suggest that null stimulation is relayed by two means: an attenuated spike frequency of individual DS cells and a desynchronization of the activity of cell ensembles.

Although dynamic modulation of cell synchrony occurs throughout the CNS, we are aware of no other example in which it is not response synchrony, but the active loss of the synchrony that forms a mechanism to encode information. Active desynchronization of cell groups has been reported in cortex (Rodriguez et al., 1999), but this appears not to have a signaling function. Rather, it is necessary for resetting cortical activity as subjects move from one cognitive state to another. The active loss of temporal correlations between ON DS cells associated with null movement thus suggests a novel mechanism by which cell groups can encode specific information.

\section{References}

Alonso JM, Usrey WM, Reid RC (1996) Precisely correlated firing in cells of the lateral geniculate nucleus. Nature 383:815-819.

Amthor FR, Takahashi ES, Oyster CW (1989) Morphologies of rabbit retinal ganglion cells with complex receptive fields. J Comp Neurol 280:97-121.

Arnett D, Spraker TE (1981) Cross-correlation analysis of the maintained discharge of rabbit retinal ganglion cells. J Physiol (Lond) 317:29-47.

Barlow HB, Hill RM, Levick WR (1964) Retinal ganglion cells responding selectively to direction and speed of image motion in the rabbit. J Physiol (Lond) 173:377-407.

Beyer EC, Paul DL, Goodenough DA (1990) Connexin family of gap junction proteins. J Membr Biol 116:87-194.

Bloomfield SA (1992) Relationship between receptive and dendritic field size of amacrine cells in the rabbit retina. J Neurophysiol 68:711-725.

Bloomfield SA, Miller RF (1986) A functional organization of ON and OFF pathways in the rabbit retina. J Neurosci 6:1-13.

Bloomfield SA, Xin D (1997) A comparison of receptive-field and tracercoupling size of amacrine and ganglion cells in the rabbit retina. Vis Neurosci 14:1153-1165.

Bloomfield SA, Xin D, Osborne T (1997) Light-induced modulation of coupling between AII amacrine cells in the rabbit retina. Vis Neurosci 14:565-576.

Brivanlou IH, Warland DK, Meister M (1998) Mechanisms of concerted firing among retinal ganglion cells. Neuron 20:527-539.

Buhl EH, Peichl L (1986) Morphology of rabbit retinal ganglion cells projecting to the medial terminal nucleus of the accessory optic system. J Comp Neurol 253:163-174.

Caldwell JH, Daw NW, Wyatt HJ (1978) Effects of picrotoxin and strychnine on rabbit retinal ganglion cells: lateral interactions for cells with more complex receptive fields. J Physiol (Lond) 276:277-298.

Castelo-Branco M, Neuenschwander S, Singer W (1998) Synchronization of visual responses between cortex, lateral geniculate nucleus, and retina in the anesthetized cat. J Neurosci 18:6395-6410.

Dacey DM (1989) Axon-bearing amacrine cells of the macaque monkey retina. J Comp Neurol 284:275-293.

Dartnell HJA (1968) The photosensitivities of visual pigments in the presence of hydroxylamine. Vis Res 8:339-358.

Davidson JS, Baumgarten IM (1988) Glycyrrhetinic acid derivatives: a novel class of inhibitors of gap-junctional intercellular communication. Structure-activity relationships. J Pharm Exp Ther 246:1104-1107.

DeMonasterio FM (1978) Spectral interactions in horizontal and ganglion cells of the isolated and arterially-perfused rabbit retina. Brain Res 150:239-258.

DeVries SH (1999) Correlated firing in rabbit retinal ganglion cells. J Neurophysiol 81:908-920.

DeVries SH, Schwartz EA (1989) Modulation of an electrical synapse between solitary pairs of catfish horizontal cells by dopamine and second messengers. J Physiol (Lond) 414:351-375.

Dodt E, Elenius V (1960) Changes in threshold during dark adaptation measured with orange and blue lights in cats and rabbits. Experimentia 16:313-314.

Dong W, Sun W, Zhang Y, Chen X, He S (2004) Dendritic relationship 
between starburst amacrine cells and direction-selective ganglion cells in the rabbit retina. J Physiol (Lond) 556:11-17.

Euler T, Detwiler PB, Denk W (2002) Directionally selective calcium signals in dendrites of starburst amacrine cells. Nature 418:845-851.

Famiglietti EV (1992a) Polyaxonal amacrine cells of rabbit retina: morphology and stratification of PA1 cells. J Comp Neurol 316:406-421.

Famiglietti EV (1992b) Polyaxonal amacrine cells of rabbit retina: size and distribution of PA2, PA3, and PA4 cells. Light and electron microscopic studies with a functional interpretation. J Comp Neurol 316:422-446.

Fried SI, Munch TA, Werblin FS (2002) Mechanisms and circuitry underlying directional selectivity in the retina. Nature 420:411-414.

Fried SI, Munch TA, Werblin FS (2005) Directional selectivity is formed at multiple levels by laterally offset inhibition in the rabbit retina. Neuron 46:117-127.

Goodenough DA, Goliger JA, Paul DL (1996) Connexins, connexons, and intercellular communication. Annu Rev Biochem 65:475-502.

He S, Masland RH (1998) ON direction-selective ganglion cells in the rabbit retina: dendritic morphology and pattern of fasciculation. Vis Neurosci 15:369-375.

Hu EH, Bloomfield SA (2003) Gap junctional coupling underlies the shortlatency synchrony of retinal alpha ganglion cells. J Neurosci 23:6768-6777.

Hu EH, Dacheux RF, Bloomfield SA (2000) A flattened retina-eyecup preparation suitable for electrophysiological studies of neurons visualized with trans-scleral infrared illumination. J Neurosci Methods 103:209-216

Kittila CA, Massey SC (1997) Pharmacology of directionally selective ganglion cells in the rabbit retina. J Neurophysiol 77:675-689.

Kogo N, Rubio DM, Ariel M (1998) Direction tuning of individual retinal inputs to the turtle accessory optic system. J Neurosci 18:2673-2684.

Kumar NM, Gilula NB (1996) The gap junction communication channel. Cell 84:381-388.

Lang EJ (2002) GABAergic and glutamatergic modulation of spontaneous and motor-cortex-evoked complex spike activity. J Neurophysiol 87:1993-2008.

Lang EJ, Sugihara I, Llinás R (1996) GABAergic modulation of complex spike activity by the cerebellar nucleoolivary pathway in rat. J Neurophysiol 76:255-275.

Liebman PA, Entine G (1964) Sensitive low-light-level microspectrophotometer: detection of photosensitive pigments of retinal cones. J Opt Soc Am 54:1451-1459.

Mangel SC, Dowling JE (1985) Responsiveness and receptive field size of carp horizontal cells are reduced by prolonged darkness and dopamine. Science 229:1107-1109.

Mastronarde DN (1983) Interactions between ganglion cells in cat retina. J Neurophysiol 49:350-365.

Meister M, Berry MJ (1999) The neural code of the retina. Neuron 22:435-450.

Meister M, Lagnado L, Baylor DA (1995) Concerted signaling by retinal ganglion cells. Science 270:1207-1210.

Miller RF, Bloomfield SA (1983) Electroanatomy of a unique amacrine cell in the rabbit retina. Proc Natl Acad Sci USA 80:3069-3073.

Nelson R, Famiglietti EV, Kolb H (1978) Intracellular staining reveals different levels of stratification for on- and off-center ganglion cells in cat retina. J Neurophysiol 41:472-483.

Neuenschwander S, Castelo-Branco M, Singer W (1999) Synchronous oscillations in the cat retina. Vis Res 39:2485-2497.

Nuboer JFW (1971) Photometry in rabbits. Doc Ophthal 30:259-278.

Oyster CW (1968) The analysis of image motion by the rabbit retina. J Physiol (Lond) 199:613-635.
Oyster CW, Simpson JI, Takahashi ES, Soodak RE (1980) Retinal ganglion cells projecting to the rabbit accessory optic system. J Comp Neurol 190:49-61.

Petit-Jacques J, Völgyi B, Rudy B, Bloomfield SA (2005) Spontaneous oscillatory activity of starburst amacrine cells in the mouse retina. J Neurophysiol 94:1770-1780.

Prince JH, McConnell DG (1964) Retinal and optic nerve. In: The rabbit in eye research (Prince JH, ed), pp 385-448. Springfield, IL: Charles C. Thomas.

Pu ML, Amthor FR (1990) Dendritic morphologies of retinal ganglion cells projecting to the nucleus of the optic tract in the rabbit. J Comp Neurol 302:657-674.

Rodriguez E, George N, Lachaux JP, Martinerie J, Renault B, Varela FJ (1999) Perception's shadow: long-distance synchronization of human brain activity. Nature 397:430-433.

Rosenberg AF, Ariel M (1991) Electrophysiological evidence for a direct projection of direction-selective retinal ganglion cells to the turtle's accessory optic system. J Neurophysiol 65:1022-1033.

Sáez JC, Berthoud VM, Branes MC, Martinez AD, Beyer EC (2003) Plasma membrane channels formed by connexins: their regulation and functions. Physiol Rev 83:1359-1400.

Schnitzer MJ, Meister M (2003) Multineuronal firing patterns in the signal from eye to brain. Neuron 37:499-511.

Simpson JI (1984) The accessory optic system. Annu Rev Neurosci 7:13-41.

Singer W (1999) Neuronal synchrony: a versatile code for the definition of relations? Neuron 24:49-65.

Singer W, Engel AK, Kreiter AK, Munk MHJ, Neuenschwander S, Roefselma PR (1997) Neuronal assemblies: necessity, signature and detectability. Trends Cognit Sci 1:252-261.

Solessio E, Vigh J, Cuenca N, Rapp K, Lasater EM (2002) Membrane properties of an unusual intrinsically oscillating, wide-field teleost retinal amacrine cell. J Physiol (Lond) 544:831-847.

Soodak RE, Simpson JI (1988) The accessory optic system of rabbit. I. Basic visual response properties. J Neurophysiol 60:2037-2054.

Spira ME, Spray DC, Bennett MV (1980) Synaptic organization of expansion motoneurons of Navanax inermis. Brain Res 195:241-269.

Stahl JS (2004) Using eye movements to assess brain function in mice. Vis Res 44:3401-3410.

Umino O, Lee Y, Dowling JE (1991) Effects of light stimuli on the release of dopamine from interplexiform cells in the white perch retina. Vis Neurosci 7:451-458.

Usrey WM, Reid RD (1999) Synchronous activity in the visual system. Annu Rev Physiol 61:435-456.

Vaney DI (1991) Many diverse types of retinal neurons show tracer coupling when injected with biocytin or Neurobiotin. Neurosci Lett 125:187-190.

Vaney DI (1994) Patterns of neuronal coupling in the retina. Prog Retina Eye Res 13:301-355.

Völgyi B, Xin D, Amarillo Y, Bloomfield SA (2001) Morphology and physiology of the polyaxonal amacrine cells in the rabbit retina. J Comp Neurol 440:109-125.

Wässle H, Reimann HJ (1978) The mosaic of nerve cells in mammalian retina. Proc R Soc Lond B Biol Sci 200:441-461.

Xin D, Bloomfield SA (1997) Tracer coupling pattern of amacrine and ganglion cells in the rabbit retina. J Comp Neurol 383:512-528.

Xin D, Bloomfield SA (1999) Dark- and light-induced changes in coupling between horizontal cells in mammalian retina. J Comp Neurol 405:75-87. 